\title{
AGE PROFILE OF CARP (CYPRINUS CARPIO L.) IN LAKE CRESCENT, TASMANIA
}

\author{
by Lorenzo Vilizzi and Keith F. Walker
}

(with five tables, four text-figures and one plate)

Vilizzi, L. \& Walker, K.F., 1998 (31:xii): Age profile of carp (Cyprinus carpio L.) in Lake Crescent, Tasmania. Pap. Proc. R. Soc. Tasm. 132: 1-8. https://doi.org/10.26749/rstpp.132.1 ISSN 0080-4703. Department of Environmental Sciences, University of Hertfordshire, College Lane, Hatfield, Hertfordshire AL1 0 9AB, UK (LV, formerly University of Adelaide); Cooperative Research Centre for Freshwater Ecology and Department of Zoology, University of Adelaide, South Australia, Australia 5005 (KFW).

Carp is an exotic, benthivorous fish implicated in degradation of wetlands throughout southeastern mainland Australia. In the present study, the age profile of a stock in Lake Crescent, Tasmania, was determined by length-frequency analysis and inspection of annulus patterns in whole and sectioned otoliths. Marginal increment analysis was attempted to validate age assessments for fish captured in 1995 and 1996. The available samples limited formal validation to age group III+, but it is clear that the January 1993 year-class was dominant among other fish of 1-6 years of age. Future monitoring should include monthly observations of age structure, reproduction and recruitment.

Key Words: fish, Cyprinidae, exotic species, otolith, validation, Lake Crescent, Lake Sorell, Tasmania.

\section{INTRODUCTION}

Lake Crescent $\left(57 \mathrm{~km}^{2}\right)$ is at $820 \mathrm{~m}$ altitude on the eastern edge of the Central Plateau in Tasmania and drains into the Clyde River. The lake supports a very minor fishery for the native short-finned eel, Anguilla australis, and there is also a recreational fishery for the exotic brown trout, Salmo trutta, and rainbow trout, Oncorhyncus mykiss. An endemic galaxiid, Galaxias auratus, is also abundant (Fulton 1990). Another exotic fish, the European carp, Cyprinus carpio L., was discovered in 1992. This was the first report of this species from Tasmania since a population was found (and later eradicated) near Burnie in the early 1970s.

Population age data are helpful to assess the suitability of control methods like poisoning, drawdown and intensive fishing (Roberts \& Tilzey 1997), and to allow determination of recruitment and year-class strength (Mann 1991). In cyprinids, scales and, to a lesser extent, opercular bones are used widely as indicators of age (Mann 1991), and otoliths (especially lapilli) also have been employed (e.g. BackeHansen 1982, Mills 1988, Mina 1989, O’Maoileidigh \& Bracken 1989). In carp there are several potentially suitable structures (Vilizzi \& Walker 1995). For example, English (1952) and Rehder (1959) found scales and opercular bones to be good indicators of age and growth, and Wichers (1976) and Bishai \& Labib (1978) judged fin rays and vertebrae, respectively, to be most convenient and reliable. No one method, however, has proved consistently effective.

The present study determined the age profile of the Lake Crescent carp stock based on length-frequency distributions and interpretation of otolith patterns, using techniques developed for carp in the River Murray, South Australia (Vilizzi \& Walker 1998; Vilizzi et al. 1998).

\section{MATERIALS AND METHODS}

\section{Samples and Preparation}

An aggregate sample of 333 fish was provided by the Inland Fisheries Commission, obtained by electrofishing and netting in February-March 1995, September-November 1995 and
January-February 1996. Four of the fish came from Lake Sorell (catchment $103 \mathrm{~km}^{2}$ ), which drains into Lake Crescent via a small artificial channel (table 1). The fish were sexed, when possible, and fork length (FL, $\pm 1.0 \mathrm{~mm}$ ) and weight $(\mathrm{W}, \pm 1.0 \mathrm{~g}$ ) determined. Otoliths (asterisci) were recovered from 189 fish. In total 75 fish were interpreted for age from whole otoliths, 58 from sectioned otoliths, and 56 from both.

Whole otoliths were viewed immersed in water, with the distal side facing the observer and the ventral margin up, using a dissecting microscope $(20-40 \mathrm{X})$ and a dark

TABLE 1

Sampling of carp in Tasmania

\begin{tabular}{|c|c|c|}
\hline Sampling site & Date $^{*}$ & $n^{\dagger}$ \\
\hline Crescent & 1.ii.1995 & 10 \\
\hline Crescent & 2.ii.1995 & 22 \\
\hline Crescent & 7.ii.1995 & 7 \\
\hline Crescent & 8.ii.1995 & 1 \\
\hline Crescent & 15.ii.1995 & 12 \\
\hline Crescent & 22.ii.1995 & 50 \\
\hline Crescent & 4.iii.1995 & 26 \\
\hline Sorell & 4.iii.1995 & 4 \\
\hline Crescent & 14.iii.1995 & 20 \\
\hline Crescent & 22.iii.1995 & 56 \\
\hline Crescent & 28.iii.1995 & 18 \\
\hline Crescent & 29.iii.1995 & 2 \\
\hline Crescent & 27.ix.1995 & 13 \\
\hline Crescent & 5.x.1995 & 8 \\
\hline Crescent & 9.xi.1995 & 2 \\
\hline Crescent & 23.xi.1995 & 20 \\
\hline Crescent & 6.i.1996 & 42 \\
\hline Crescent & 14.ii.1996 & 1 \\
\hline Crescent & 21.ii.1996 & 19 \\
\hline
\end{tabular}

* Date of collection of carp in Tasmania.

$\dagger$ Indicates the sample size and number of fish interpreted for age (whole and sectioned otoliths). 
background (reflected oblique light). Under these conditions, an annulus was defined as a transition between a translucent (dark) and an opaque (light) zone. Annuli were counted on the distal side of the otolith, along the antero-dorsal region, at the level of the dorsal spike, a projection analogous to the antirostrum of the nonotophysan teleost sagitta (Pannella 1980) (pl. 1).

When possible, the left otolith of each pair was embedded in clear polyester resin in $8 \mathrm{~mm}$ thick blocks (about $62 \mathrm{~mm}^{2}$ ), each containing 10-14 otoliths (depending on their size) with their nuclei carefully aligned. Three successive transverse sections $(0.4-0.5 \mathrm{~mm})$ were cut through the nucleus, using a low-speed lapidary saw (Augustine \& Kenchington 1987). Sections were polished with 1200-grit carborundum paper to enhance the visibility of the zones. The sections were examined under the same lighting conditions used for analysis of whole otoliths (transmitted light proved unsatisfactory).

\section{Validation and Age Adjustment}

Validation was based on marginal increment analysis (MIA) (Bagenal \& Tesch 1978), including marginal increment ratio analysis (MIRA) and edge type analysis (ETA) (Haas \&
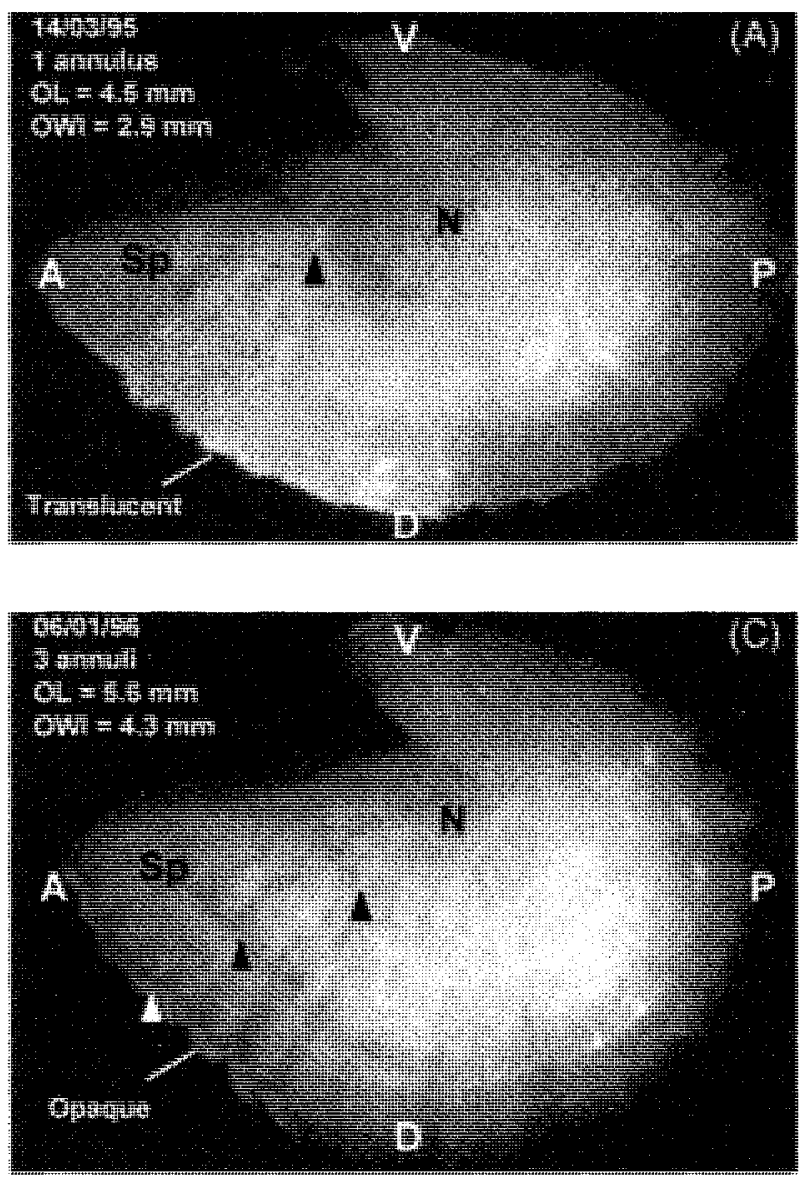

Recksiek 1995), with regard for the "edge interpretation problem" (Francis et al. 1992). MIA elucidates relationships between the spatial patterns seen in calcified structures and the temporal patterns caused by environmental changes. The marginal increment ratio (MIR) was calculated as

$$
\operatorname{MIR}=[(\mathrm{NE}-\mathrm{NLA}) /(\mathrm{NLA}-\mathrm{NSA})] \times 100
$$

where $\mathrm{NE}=$ distance from nucleus to outer edge, NLA = distance from nucleus to last-formed annulus, and NSA = distance from nucleus to second-last-formed annulus. Where there was only one annulus the denominator becomes the distance from nucleus to annulus. The edges of otoliths were recorded as "opaque" or "translucent", and, for the edge type analysis, the last-formed annulus was judged as $\mathrm{C}$ ("close") (MIR 50\%), Z (other) (50\% < MIR < 75\%) or $\mathrm{N}$ ("now due") (MIR 75\%), using a technique modified after Anderson et al. (1992a, b).

Age adjustments allowing for the time of capture and the relative growth of whole and sectioned otoliths followed the procedure of Vilizzi \& Walker (1998), with minor modifications. January 1 was taken as the nominal birthdate of each annual cohort. This date corresponded to the onset of a protracted period of mean water temperatures exceeding $15^{\circ} \mathrm{C}$, the minimal spawning threshold for carp
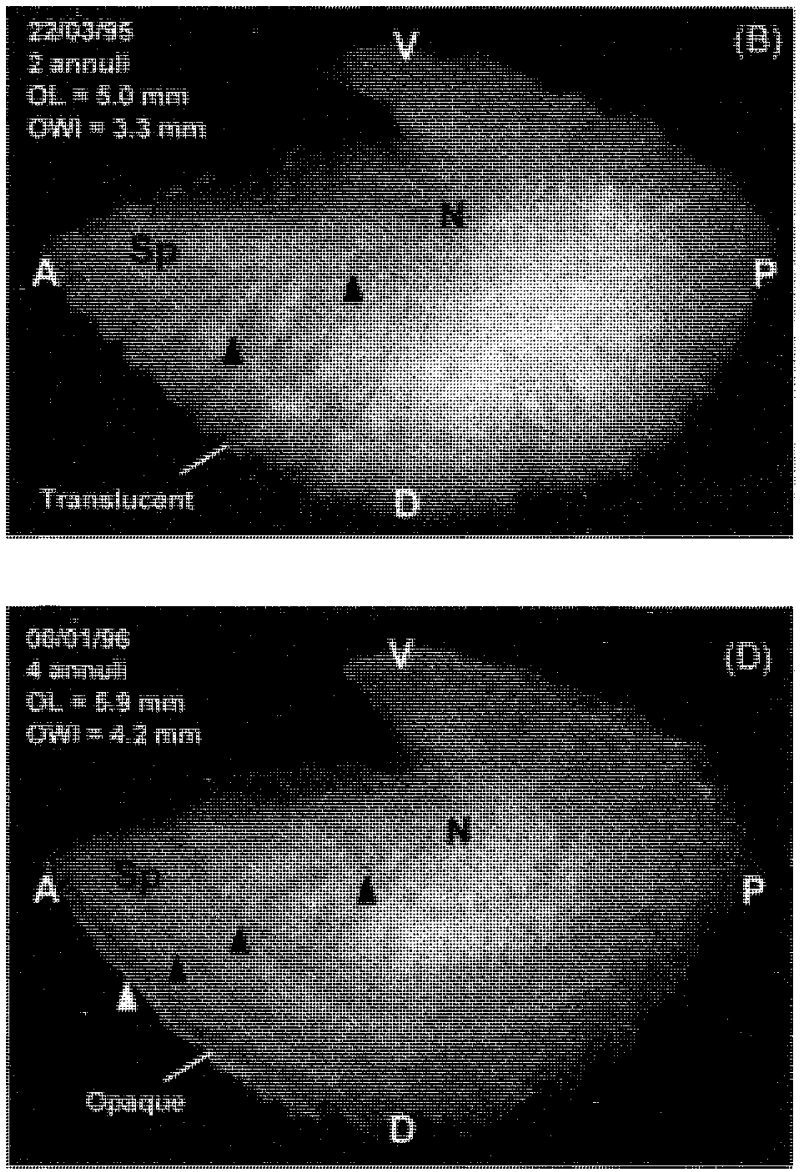

PLATE 1

Otoliths (asterisci) from Lake Crescent carp, Tasmania. Under reflected oblique light on a dark background an annulus is a transition between a translucent (dark) and an opaque (light) zone, here indicated with a triangle. The edge type (i.e. opaque or translucent), the date of capture of the fish and the number of annuli are reported. Sp, antero-dorsal spike; A, anterior edge; $\mathrm{P}$, posterior edge; $\mathrm{D}$, dorsal edge; $\mathrm{V}$, ventral edge; $\mathrm{N}$, nucleus; $\mathrm{OL}$, otolith length; $\mathrm{OW}$, otolith width. (A) 1 annulus, translucent edge, late summer; (B) 2 annuli, translucent edge, late summer; (C) 3 annuli, newly-formed opaque zone, summer; (D) 4 annuli, opaque edge, summer. 
(Sarig 1966, Guha \& Mukherjee 1991). The age of a fish with MIR 50\% (new annulus forming), caught in November or December, was reduced by one year, regardless of the number of annuli. Similarly, the apparent age of a fish caught in January with MIR 75\% (new annulus due) was increased by one year regardless of the number of annuli. In February, the age of a fish with more than one annulus but about to form a new annulus (MIR 75\%) was increased by one year and, in March, the same adjustment was applied to fish with more than two annuli and MIR 75\%. Adjustments were not needed for fish caught from April to October (table 2).

\section{Analysis}

Length-frequency data and MIA were used to estimate the age composition of the stock. Fork lengths for the three different catches were compared by one-way ANOVA, and mean annulus distances from the nucleus in otoliths of carp from Lakes Crescent and Sorell, and from the River Murray in South Australia (Vilizzi \& Walker 1998) were compared by two-way ANOVA (sampling location x number of annuli). Differences between means were evaluated using Tukey's HSD test for unequal sample sizes (Spjotvoll \& Stoline 1973). Comparisons of growth in males and females, analyses of residuals and validation of parametric methods followed Vilizzi \& Walker (1998).

\section{RESULTS}

\section{Length-Frequency Analysis}

Length-frequency distributions for each of the three subsamples were approximately uni-modal. ANOVA and post hoc comparisons indicated no significant difference in FL in 1995 (fig. 1A, B), but the mean FL for the 1996 catch was higher than for either catch in $1995(P<0.001)$ (fig. 1C).

TABLE 2

Adjustments to annulus counts* for carp in Lakes Crescent and Sorell, Tasmania

\begin{tabular}{|c|c|c|c|}
\hline $\begin{array}{l}\text { Month of } \\
\text { capture }\end{array}$ & Annuli $^{\dagger}$ & $\begin{array}{c}\mathrm{MIR}^{\ddagger} \\
(\%)\end{array}$ & $\begin{array}{c}\text { Estimated age } \\
(y)\end{array}$ \\
\hline Jan & & 75 & Annuli +1 \\
\hline \multirow[t]{2}{*}{ Feb } & 1 & & 1 \\
\hline & 2 & 75 & Annuli +1 \\
\hline \multirow[t]{2}{*}{ Mar } & 2 & & Annuli \\
\hline & 3 & 75 & Annuli +1 \\
\hline $\mathrm{Apr}-\mathrm{Oct}$ & & & Annuli \\
\hline Nov-Dec & & 50 & Annuli - 1 \\
\hline
\end{tabular}

* Based on a nominal birth-date of 1 January for each annual cohort.

$\dagger$ Number of annuli counted on the calcified structure.

$\ddagger$ MIR: marginal increment ratio

\section{Interpretability of Otoliths}

Three (2.3\%) of the 131 whole otoliths and 21 (18.4\%) of the 114 sectioned otoliths were discarded as "uninterpretable". Interpretability was significantly lower for sectioned otoliths $\left(\chi^{2}=17.95, P<0.001\right)$.

\section{Validation of Annulus Counts}

As comparisons of whole and sectioned otoliths showed no differences in the time of annulus formation and edge characteristics, data for whole otoliths only are considered below. In the following, therefore, "otolith" may be taken to mean either whole or sectioned preparations.

In otoliths with two annuli, MIR remained high throughout the year, peaking in January (fig. 2A). In otoliths with three annuli, a decline in MIR was visible through January (15.5\%) and February (26.5\%); this rose sharply in March and decreased toward the end of the year (fig. 2B). When annulus groups $1-5$ were pooled, a different trend

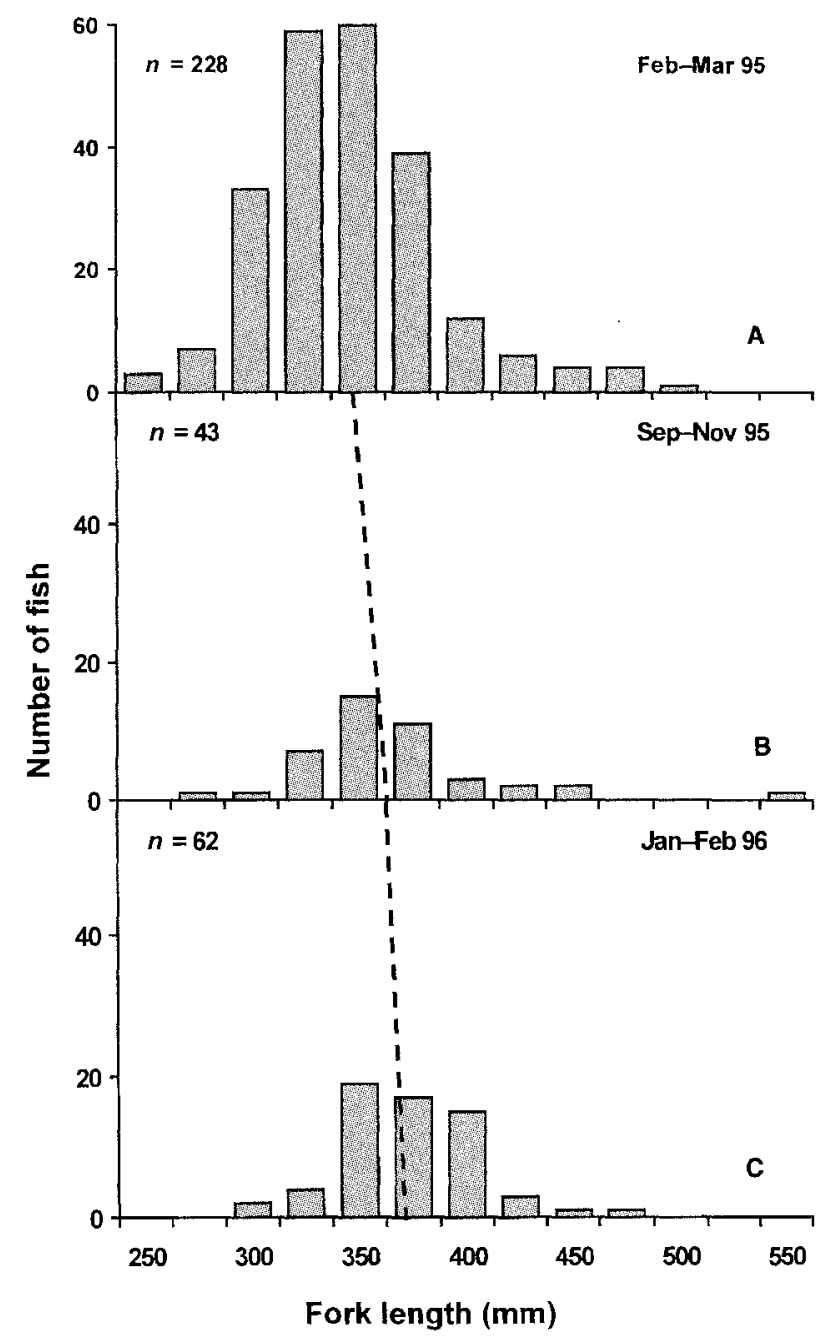

FIG. 1 - Length-frequency distributions of carp from Lakes Crescent and Sorell, Tasmania. Mean fork length values for each sub-sample are joined by a broken line. (A) Combined data for February-March 1995, (B) September-November 1995, (C) January-February 1996 
2 annuli

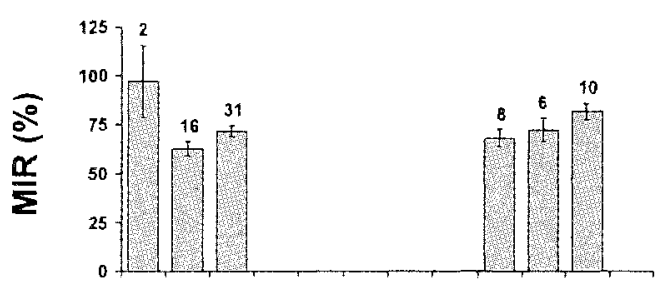

A

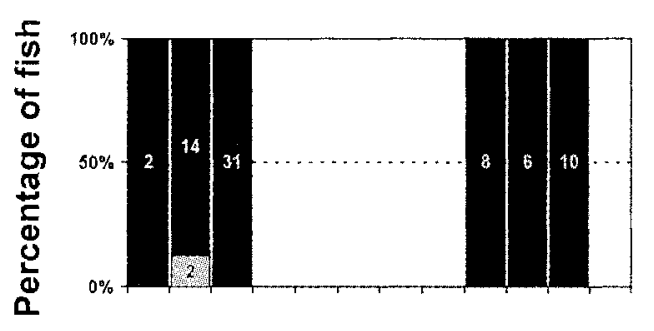

C

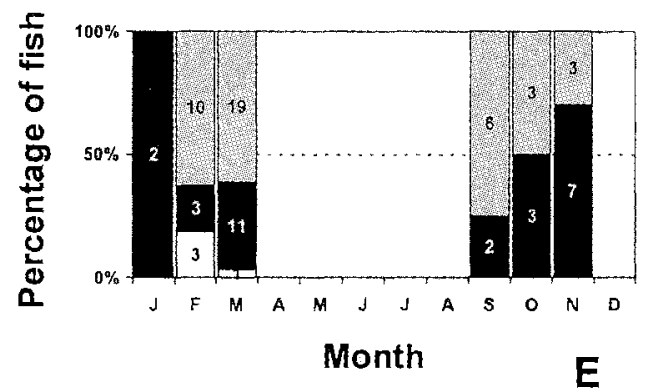

3 annuli

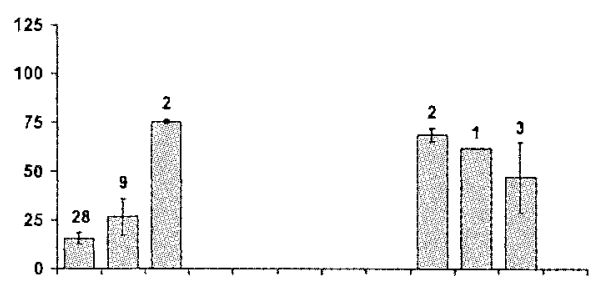

B

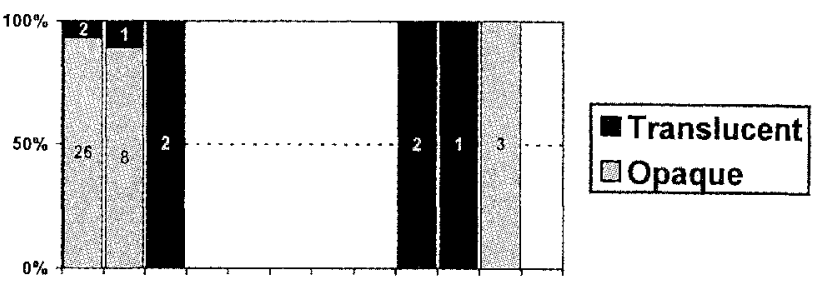

D

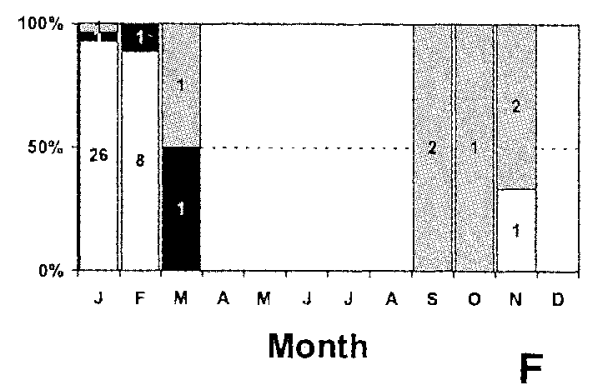

FIG. 2 - Marginal increment analysis of whole otoliths from carp in Lakes Crescent and Sorell, Tasmania. Data for 2 ( $A, C, E)$ and $3(B, D, F)$ annuli are shown: $(A, B)$ mean monthly values ( $\pm S E)$ of the marginal increment ratio (MIR), as a percentage of the previous increment, $(C, D)$ percentage of fish having otoliths with an opaque or a translucent edge (under transmitted light), $(E, F)$ percentage of fish scored as $\mathrm{C}$ (MIR 50\%), Z (25\%<MIR $<75 \%)$, or $\mathrm{N}$ (MIR 75\%).

was observed. A decline in MIR was apparent in January, when it fell to $25.9 \%$. This increased in February and remained high in November $(74.0 \%)$, one month before the nominal birth-date (fig. $3 \mathrm{~A}$ ).

Otoliths with two annuli almost always had a translucent edge (fig. 2C), while newly-formed opaque edges were especially common in carp with three annuli captured in January (when most specimens were caught) (fig. 2D). In pooled annulus groups, the percentage of otoliths with an opaque edge was high in January and February but markedly lower in March, when most had a translucent margin. Translucent margins were observed also in fish caught in September-November (fig. 3B).

In annulus group 2 , there were few otoliths with type $C$ edges, observed in February and March. This is unexpected, given the distribution of edge types (fig. 2E). A pattern comparable to that noted for MIR and ETA was apparent in annulus group 3, although type $Z$ rather than type $N$ edges predominated in early spring (fig. $2 \mathrm{~F}$ ). In pooled annulus groups, type $\mathrm{C}$ otoliths were more abundant in January and February, and the proportions of type $\mathrm{N}$ and $Z$ edges increased in November and March-September, respectively (fig. 3C).

\section{Annulus Distance}

The mean annulus distance from the nucleus in whole (1-6 annuli) and sectioned otoliths (1-4 annuli) increased progressively, supporting the suggestion that ages estimated from annulus counts did reflect true ages (fig. 4A, B). The mean distance from the nucleus of the first three annuli in whole otoliths from River Murray carp was significantly less than that from Lakes Crescent and Sorell $(P<0.001)$ and, as would be expected, there were significant differences among the mean distances from the nucleus of the first three annuli $(P<0.001)$ (table 3$)$.

\section{Length-Weight Relationships}

The lengths and weights of juveniles, males and females are summarised in table 4. Estimated ages were based on whole or sectioned otoliths and, when both were available for one specimen, the whole otolith was arbitrarily used. Lengthweight relationships were modelled for all aged fish (pooled sexes and juveniles). Growth parameters are shown in table 5. 

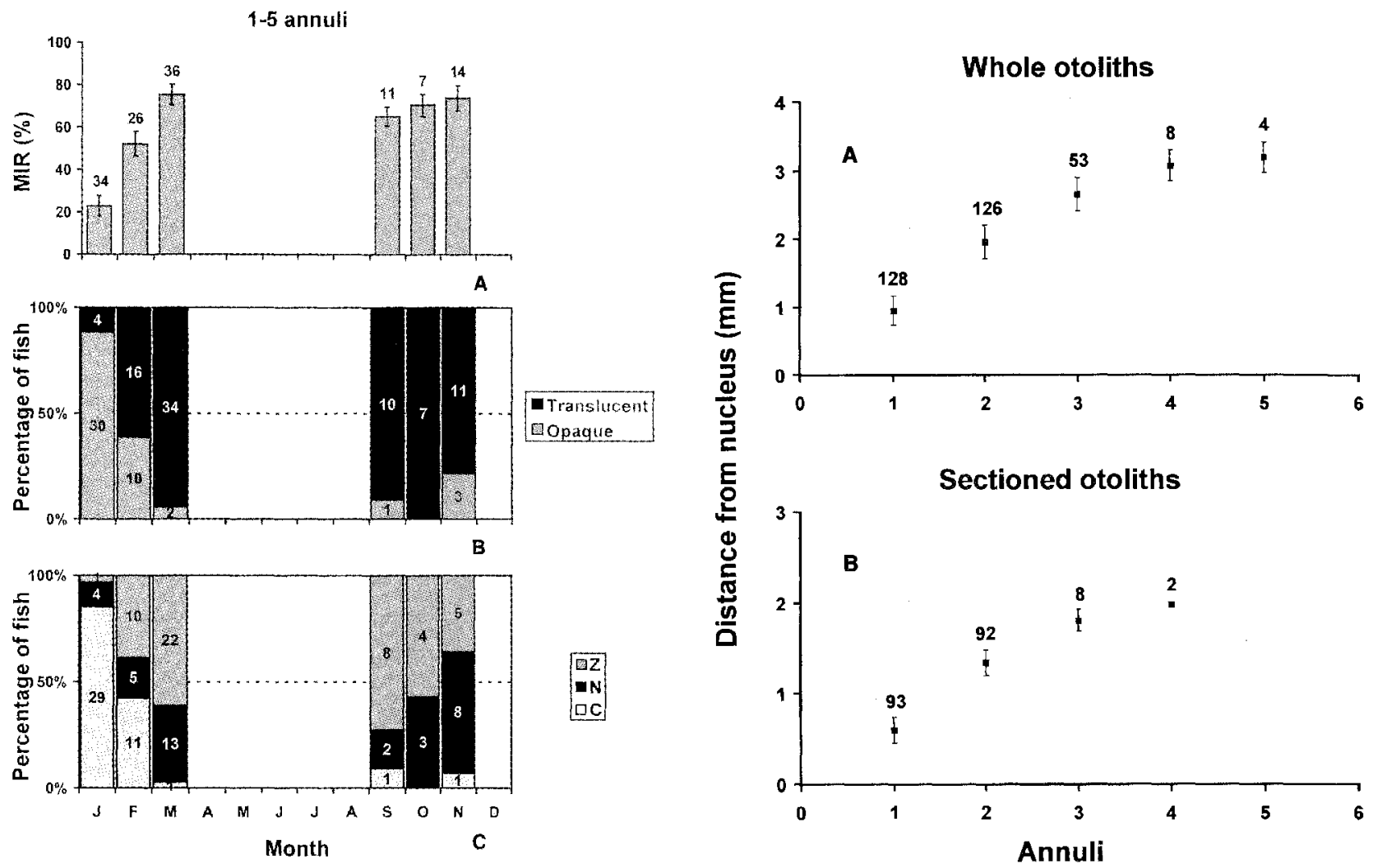

FIG. 3-Marginal increment analysis of whole otoliths from carp in Lakes Crescent and Sorell, Tasmania (pooled annulus groups only): (A) mean monthly values ( $\pm S E$ ) of the marginal increment ratio $(M I R)$, as a percentage of the previous increment; (B) percentage of fish having otoliths with an opaque or a translucent edge (under transmitted light); (C) percentage of fish scored as C (MIR 50\%), Z (25\% $<M I R<75 \%)$, or $\mathrm{N}(M I R \quad 75 \%)$.

FIG. 4- Mean annulus distance from the nucleus $( \pm S D)$ in carp otoliths from Lakes Crescent and Sorell, Tasmania. Annulus counts are based on the corresponding structure. (A) Whole otoliths; (B) sectioned otoliths.

TABLE 3

Distance of annulus from nucleus in whole otoliths compared for carp in two states

\begin{tabular}{|c|c|c|c|c|c|c|c|c|c|c|}
\hline \multirow[b]{3}{*}{ Annulus } & \multicolumn{10}{|c|}{ Annulus distance from nucleus (mm) } \\
\hline & \multicolumn{5}{|c|}{ Lakes Crescent and Sorell, Tasmania } & \multicolumn{5}{|c|}{ River Murray, South Australia } \\
\hline & $n$ & Mean & $\pm \mathrm{SE}$ & Min & $\operatorname{Max}$ & $n$ & Mean & $\pm \mathrm{SE}$ & Min & $\operatorname{Max}$ \\
\hline 1 & 128 & 0.947 & 0.019 & 0.56 & 1.83 & 417 & $1 \cdot 145$ & 0.014 & 0.51 & $2 \cdot 26$ \\
\hline 2 & 126 & 1.966 & 0.022 & 1.48 & $2 \cdot 60$ & 367 & $2 \cdot 260$ & 0.023 & 1.09 & $3 \cdot 50$ \\
\hline 3 & 53 & 2.664 & 0.034 & $2 \cdot 01$ & $3 \cdot 15$ & 358 & $2 \cdot 818$ & 0.026 & 1.42 & 4.02 \\
\hline 4 & 8 & 3.078 & $0 \cdot 081$ & $2 \cdot 71$ & $3 \cdot 38$ & 301 & 3.284 & 0.030 & 1.82 & 4.47 \\
\hline 5 & 4 & 3.200 & 0.112 & 2.94 & 3.46 & 190 & 3.691 & 0.042 & $2 \cdot 12$ & 4.95 \\
\hline
\end{tabular}


TABLE 4

Summary fork length (FL) and weight (W) of juvenile, male and female carp from Lakes Crescent and Sorell, Tasmania

\begin{tabular}{|c|c|c|c|c|c|c|c|c|c|}
\hline \multirow[b]{2}{*}{ Age $(y)^{*}$} & \multirow[b]{2}{*}{$n$} & \multicolumn{4}{|c|}{$\mathrm{FL}(\mathrm{mm})$} & \multicolumn{4}{|c|}{$\mathrm{W}(\mathrm{g})$} \\
\hline & & Mean & $\pm \mathrm{SE}$ & Min & Max & Mean & $\pm \mathrm{SE}$ & Min & $\operatorname{Max}$ \\
\hline \multicolumn{10}{|l|}{ Juveniles } \\
\hline 1 & 2 & 296.0 & 26.0 & 270 & 322 & 669.0 & 111.0 & 558 & 780 \\
\hline 2 & 29 & 317.6 & 6.2 & 228 & 375 & 823.9 & 40.8 & 316 & 1316 \\
\hline 3 & 3 & 305.7 & 22.2 & 283 & 350 & 722.3 & 159.0 & 552 & 1040 \\
\hline \multicolumn{10}{|l|}{ Males } \\
\hline 1 & 1 & 315 & & & & 874 & & & \\
\hline 2 & 39 & 341.9 & 4.3 & 273 & 400 & 1036.0 & 39.4 & 458 & 1520 \\
\hline 3 & 41 & 335.9 & 4.5 & 282 & 420 & 988.5 & 40.8 & 546 & 1778 \\
\hline 4 & 4 & 367.0 & 23.4 & 302 & 407 & 1309.3 & 265.3 & 594 & 1765 \\
\hline 5 & 2 & 435.5 & 19.5 & 416 & 455 & 1659.0 & 345.0 & 1314 & 2004 \\
\hline \multicolumn{10}{|l|}{ Females } \\
\hline 2 & 20 & 341.5 & 4.7 & 300 & 370 & 1046.0 & 54.8 & 600 & 1485 \\
\hline 3 & 29 & 362.1 & 6.8 & 300 & 441 & 1238.9 & 77.7 & 681 & 2200 \\
\hline 4 & 4 & 395.3 & 22.6 & 348 & 455 & 1733.5 & 351.1 & 1012 & 2662 \\
\hline 5 & 1 & 417 & & & & 1615 & & & \\
\hline 6 & 1 & 528 & & & & 4275 & & & \\
\hline
\end{tabular}

* Estimated ages are based on annulus counts from whole and sectioned otoliths, in that order.

TABLE 5

Length-weight relationships for carp in Lakes Crescent and Sorell, Tasmania

\begin{tabular}{|c|c|c|c|c|}
\hline Parameters* & All fish & Males + Females & Males & Females \\
\hline$n$ & 332 & 255 & 168 & 87 \\
\hline $\mathrm{a}$ & $3 \cdot 5 \mathrm{E}-08$ & $3 \cdot 9 \mathrm{E}-08$ & $1 \cdot 1 \mathrm{E}-07$ & $2 \cdot 1 \mathrm{E}-08$ \\
\hline b & 2.943 & 2.927 & 2.753 & 3.028 \\
\hline$r^{2}$ & 0.900 & 0.987 & 0.989 & 0.986 \\
\hline $\mathrm{RSS}^{\dagger}$ & & 4.694 & $2 \cdot 179$ & 2.411 \\
\hline $\mathrm{DF}$ & & 253 & 166 & 85 \\
\hline F & & $2.840(P=0.060)$ & & \\
\hline Model ${ }^{\ddagger}$ & $\mathrm{W}=3.5 \mathrm{E}-08 \mathrm{FL}^{2.943}$ & $\mathrm{~W}=3.9 \mathrm{E}-08 \mathrm{FL}^{2.927}$ & $\mathrm{~W}=1 \cdot 1 \mathrm{E}-07 \mathrm{FL}^{2.753}$ & $\mathrm{~W}=2 \cdot 1 \mathrm{E}-08 \mathrm{FL}^{3.028}$ \\
\hline
\end{tabular}

* Values for the parameters and tests of significance between sexes are shown (asymptotic standard errors were not available). $\dagger$ The residual sum of squares (RSS) and the value and probability for the $F$-ratio test are indicated for comparisons between sexes. Since no significant differences were detected $(\alpha=0.05)$ the pooled model is specified.

\$ Logarithms are to base $10 ; \mathrm{E}$, exponential notation; FL, fork length $(\mathrm{mm})$; W, weight $(\mathrm{kg})$.

\section{Discussion}

Formal validation of age assessments (sensu Beamish \& McFarlane 1983) by MIA was limited to otoliths for threeyear-old fish. Even so, the patterns of otolith development in two-year-old individuals (except in the January sample), and the relative distance of annuli from the nucleus in otoliths from all annulus groups in the stock, point to deposition of annual bands over $1-5$ years.

The apparent lack of a new annulus in two-year-old fish at the beginning of the growing season (January-February) was perplexing: the mean MIR and the edges of otoliths with two annuli were typical of fish about to form a new annulus, and inconsistent with the low marginal increments and narrow opaque edges expected from annual deposition of bands. This probably was an artefact of the method used, given the presence of a single dominant year-class and the lack of younger age groups. The length-frequency analyses clearly showed that a single cohort dominated, consisting of age-group II individuals in 1995 and group III individuals in 1996 (notations here follow Jearld 1983). Age-group I carp, on the other hand, were not abundant in the samples (two individuals in February, one in March 1995). If an arbitrary $300 \mathrm{~mm} \mathrm{FL}$ is used to separate I+ and $\mathrm{II}+$ individuals (cf. pl. 1), age-group I was inconspicuous in 1995 and probably absent in 1996.

Validation of annulus counts by MIA was based on the most abundant 1993 year-class. Two specimens caught in 
January 1996 accounted for the peak MIR value and the presence of "aberrant" edge types; these probably were fish yet to form the new annulus laid down by other members of the same age group. All carp with two annuli (except the two specimens captured in January) were caught in 1995 , and specimens with three annuli sampled during JanuaryFebruary 1996 belonged to the same cohort. The few III+ specimens caught in September-November 1995 almost certainly were members of the 1992 cohort, which was represented by only two individuals in the January 1996 sample. For similar reasons, the low mean MIR for threeyear old carp in January 1996 also is probably atypical, as it relates to the dominant 1993 cohort and does not include three-year-old fish about to form an annulus at the inception of their fourth year (this is the low-abundance January 1992 cohort).

The data presented here complement studies on carp in the River Murray (Vilizzi \& Walker 1998, Vilizzi et al. 1998) and illustrate the tolerance of age estimates to changes in the timing of reproduction. In early 1995, the period with water temperatures above the spawning threshold lasted for three weeks. However, the 1996 summer was atypical, as a rise in water temperatures above the threshold would have been expected in mid-November. This has important consequences for the estimation of a birth-date. In the present study, 1 January was chosen, based on mean water temperatures and annulus formation in otoliths; however, a more precise estimate would be obtained by future monitoring of year-to-year variation in mean temperatures in the lakes and of carp reproduction. Further, an advantage with the proposed age adjustment methodology is that difficulties in interpreting results for small sample sizes and/or pronounced annual variation in recruitment are buffered, so that atypical individuals are assigned to the correct annulus group. The versatility of the method, a mathematical implementation to graphical representations of the edge interpretation problem (Francis et al. 1992), becomes evident if the following is postulated. In the unlikely case of a fish stock where all age classes form an annulus at the same time (birth-date), hence regardless of their age, no adjustment would be necessary, and the use of the annulus count corrections would simply have a null effect. Since variation in time of annulus formation is likely to be present in most fish stocks, adjustments are made whenever required.

The smaller widths of successive annuli in Lakes Crescent and Sorell carp may reflect more severe local climatic conditions compared to those in the River Murray, and may explain the lower readability of sectioned compared to whole otoliths. In the otoliths of Lakes Crescent and Sorell carp, translucent zones (under transmitted light) appeared as dark, thin areas intercalated with wider opaque zones, and the alternations were not clear after sectioning. The narrow bands of Lakes Crescent and Sorell carp may reflect a shorter slow-growth period than in the River Murray, where temperatures exceed $15^{\circ} \mathrm{C}$ for most of the year (Jones 1974).

\section{ACKNOWLEDGEMENTS}

We are grateful to Andrew Sanger and John Diggle, Inland Fisheries Commission, Hobart, for providing the sample of carp upon which this analysis is based and for comments on a draft manuscript. We are also indebted to David McGlennon and Bruce Jackson, South Australian Research and Development Institute, Adelaide, who provided access to equipment for sectioning otoliths.

\section{REFERENCES}

Anderson, J.R., Morison, A.K. \& Ray, D., 1992a: Age and growth of Murray cod, Maccullochella peeli (Perciformes: Percichthyidae), in the Lower Murray-Darling Basin, using thin-sectioned otoliths. Aust. J. Mar. Freshw. Res. 43: 983-1013.

Anderson, J.R., Morison, A.K. \& Ray, D., 1992b: Validation of the use of thin-sectioned otoliths for determining the age and growth of golden perch, Macquaria ambigua (Perciformes: Percichthyidae), in the Lower MurrayDarling Basin, Australia. Aust. J. Mar. Freshw. Res. 43 : $1103-1128$.

Augustine, O. \& Kenchington, T.J., 1987: A low-cost saw for sectioning otoliths. J. Cons., Cons. Int. l'Explor. Mer 43: 296-298.

BAGENAL, T.B. \& TeSCH, F.W., 1978: Age and growth. In Bagenal, T.B. (Ed.): METHODS FOR ASSESSMENT OF FISH PRODUCTION IN FRESH WATERS. Blackwell, Oxford: 101-136.

BACKE-HANSEN, P., 1982: Age determination, growth and maturity of the bleak Alburnus alburnus (L.) (Cyprinidae) in Lake Øyeren, SE Norway. Fauna Norv. Ser. A 3: 31-36.

Beamish, R.J. \& McFarlane, G.A., 1983: The forgotten requirement for age validation in fisheries biology. Trans. Am. Fish. Soc. 112: 735-743.

BiSHAI, H.M. \& LABrB, W.D., 1978: Age and growth of mirror carp (Cyprinus carpio L.) at Serow Fish Farm. Bull. Inst. Oceanogr. Fish. 8: 397-418.

ENGLISH, T.S., 1952: Growth studies of the carp, Cyprinus carpio Linnaeus, in Clear Lake, Iowa. Iowa State Coll. J. Sci. 24: 527-540.

Francis, R.I.C.C., Paul, L.J. \& Mulligan, K.P., 1992: Ageing of adult snapper (Pagrus auratus) from otolith annual ring counts: validation by tagging and oxytetracycline injection. Aust. J. Mar. Freshw. Res. 43: 1069-1089.

FULTON, W., 1990: Tasmanian freshwater fisheries. FAUNA OF TASMANIA HANDBOOK 7. University of Tasmania \& Inland Fisheries Commission, Tasmania.

Guha, D. \& Mukherjee, D., 1991: Seasonal changes in the gonadal activity of common carp, Cyprinus carpio Linn. Indian J. Fish. 38: 218-23.

HAAS, R.E. \& RECKSIEK, C.W., 1995: Age verification of winter flounder in Narragansett Bay. Trans. Am. Fish. Soc. 124: 103-111.

Jearld, A. JR, 1983: Age determination. In Johnson, D.L. \& Lampton, S.S. (Eds): FISHERIES TECHNIQUES. American Fisheries Society, Bethesda, Maryland: 301324.

JONES, W., 1974: Age determination and growth studies of four species of fish from the River Murray. Unpubl. BSc Hons thesis, Dept Zool., Univ. Adelaide: 113 pp.

MANN, R.H.K., 1991: Growth and production. In Winfield, I.J. \& Nelson, J.S. (Eds): CYPRINID FISHES: SYSTEMATICS, BIOLOGY AND EXPLOITATION. Chapman \& Hall, London: $456-482$.

Mills, C.A., 1988: The effect of extreme northerly climatic conditions on the life history of the minnow, Phoxinus phoxinus (L.). J. Fish Biol. 33: 545-561.

Mina, M.V., 1989: Use of otoliths for age determination of cyprinid fishes. J. Ichthyol. 29 (7): 142-149.

O'MaOlleidigh, N. \& Bracken, J.J., 1989: Biology of the tench, Tinca tinca (L.), in an Irish lake. Aquacult. Fish. Manage. 20: 199-209. 
PANnelia, G., 1980: Growth patterns in fish sagittae. In Rhoads, D.C. \& Lutz, R.A. (Eds): SKELETAL GROWTH OF AQUATIC ORGANISMS. Plenum Press, New York: $519-560$.

ReHDER, D.D., 1959: Some aspects of the life history of the carp, Cyprinus carpio, in the Des Moines River, Boone County, Iowa. lowa State J. Sci. 34: 11-26.

ROBERTS, J. \& TLLZEY, R. (Eds) (1997): CONTROLLING CARP: EXPLORING THE OPTIONS FOR AUSTRALIA. CSIRO Land and Water, Canberra: $132 \mathrm{pp}$.

SARIG, S., 1966: Synopsis of biological data on common carp (Cyprinus carpio L. 1758) (Near-East and Europe). FAO Fisheries Synopsis 31: 39 pp.

Spjotvoll, E. \& STOLIne, M.R., 1973: An extension of the Tmethod of multiple comparison to include the cases with unequal sample sizes. J. Am. Stat. Assoc. 68: 976-978.
VILIZZI, L. \& WALKER, K.F., 1995: Otoliths as potential indicators of age in common carp, Cyprinus carpio L. (Cyprinidae: Teleostei). Trans. R. Soc. S. Aust. 119: 97-98.

VILIZZI, L. \& WALKER, K.F., 1998: Age and growth of carp, Cyprinus carpio L. (Cyprinidae), in the River Murray, Australia: validation, consistency of age interpretation and growth models. Environ. Biol. Fishes (in press).

Vilizzi, L., Walker, K.F., Jain, T., McGlennon, D. \& Tsymbal, V., 1998: Interpretability and precision of annulus counts for calcified structures in carp Cyprinus carpio L. Arch. für Hydrobiol. (in press).

WICHERS, W.F., 1976: Age and growth of carp (Cyprinus carpio) from Pathfinder Reservoir, Wyoming, 1974 and 1975. NOAA (National Marine Fisheries Service) Washington, D.C.: 69 pp.

(accepted 5 May 1998) 